\title{
Perancangan Kartu Kuartet sebagai Media Pengenalan Dasar Tanaman Obat dengan Teknik Ilustrasi Botani untuk Remaja Usia 12-15 Tahun
}

\author{
Titah Utami ${ }^{1}$, Aditya Nirwana ${ }^{2}$ \\ 12 Program Studi Desain Komunikasi Visual, Universitas Ma Chung, Villa Puncak Tidar N-01, Kota Malang, \\ Indonesia, 65151
}

Correspondence: Titah Utami (331710022@student.machung.ac.id) Received: 160721 - Revised: 020821 - Accepted: 150821 - Published: DD MM YY

\begin{abstract}
Abstrak. Tanaman obat merupakan sekelompok jenis tanaman yang dapat dimanfaatkan oleh masyarakat untuk menjaga kesehatan, memperbaiki gizi, dan menghijaukan lingkungan. Kurangnya pengetahuan masyarakat mengenai tanaman obat di Indonesia berdampak pada kurangnya pemanfaatan dari tanaman tersebut sebagai upaya preventif dan kuratif bagi kesehatan masyarakat. Maka dari itu, diperlukan edukasi dan sosialisasi mengenai tanaman obat, terutama kepada kalangan muda. Kartu kuartet memiliki manfaat edukatif melalui gambar sebagai visualisasi dan tulisan sebagai keterangan objek yang terlihat. Hal ini dapat meningkatkan minat dan ketertarikan untuk mempelajari tanaman obat. Rancangan kartu kuartet tanaman obat disertai elemen Victorian, di sketsa dengan teknik ilustrasi botani bergaya naturalis yang divisualisasikan menggunakan teknik eyeballing. Pada kartu kuartet juga dikombinasikan dengan motif kawung guna mengangkat batik sebagai salah satu budaya Indonesia. Didapatkan 1 set kartu kuartet yang terdiri dari 32 kartu dengan delapan kategori yaitu: buah, biji, kulit pohon, aromatik, rimpang, daun, bunga, dan pohon. Dalam rancangan termasuk kemasan kartu kuartet dan instruksi permainan serta website dan akun Instagram sebagai media promosi. Hasil data uji coba kartu kuartet pada delapan orang remaja usia 12-15 tahun didapatkan peningkatan yang signifikan dalam mengenali macam tanaman obat.
\end{abstract}

Kata kunci: kuartet, tanaman obat, ilustrasi botani

Citation Format: Utami, T. \& Nirwana, A. (2021). Perancangan Kartu Kuartet sebagai Media Pengenalan Dasar Tanaman Obat dengan Teknik Ilustrasi Botani untuk Remaja Usia 12-15 Tahun. Prosiding Seminar Nasional Abdimas Ma Chung (SENAM), 2021, 37-49 


\section{PENDAHULUAN}

Kartu kuartet merupakan salah satu media pembelajaran alternatif yang dapat menyampaikan informasi dalam bentuk visual atau gambar (Karsono, et al, 2014). Telah ditemukan bahwa tingkat pemahaman siswa sekolah dasar mengenai keberagaman seni tradisi nusantara meningkat dari 6,67\% menjadi 93,33\% setelah menggunakan kartu kuartet dalam proses pembelajaran. Menurut Hasanah (2019), keunggulan media kartu dibandingkan media elektronik adalah 1) Praktis; 2) Membuat proses pembelajaran lebih aktif dan kreatif; 3) Informasi disajikan dengan lebih konkrit dan realistis; 4) Mengasah kemampuan motorik; 5) Visual sebagai elemen yang mudah ditangkap. Namun, kelemahan dari media kartu fisik adalah gambar yang hanya menafsirkan indera mata dan ukuran gambar yang terlalu kecil dapat mengurangi efektivitas proses pembelajaran (Sadminan, 2008).

Tanaman obat adalah sebutan untuk sekelompok jenis tanaman yang dapat dimanfaatkan oleh masyarakat untuk menjaga kesehatan, memperbaiki gizi, dan menghijaukan lingkungan (Ziraluo, 2020). Akan tetapi, pemanfaatan dan pengetahuan masyarakat mengenai tanaman obat masih minim, terbukti dari survei pasien yang berkunjung ke Puskesmas Air Tabit dimana 11,4\% responden mengenali tanaman obat serta manfaatnya dan 88,6\% responden kesulitan mengidentifikasi tanaman tersebut (Erlindawati, 2015). Hal ini menunjukkan perlunya sosialisasi dengan masyarakat mengenai tanaman obat agar dapat dikembangkan lebih lanjut pemanfaatannya sebagai upaya preventif dan kuratif untuk meningkatkan derajat kesehatan masyarakat (Emilda dan Heriyati, 2017).

Pengenalan informasi mengenai tanaman obat secara visual dapat disampaikan menggunakan ilustrasi botani yang berperan penting sebagai referensi ilmiah dan aliran seni (Humphrey, 2018). Penyampaian informasi melalui kartu kuartet, baik dari gambar maupun tulisan, menurut University of Rochester Medical Center (2021), remaja usia 12 hingga 15 tahun dinilai mampu melakukan pemikiran yang lebih kompleks serta memiliki kemampuan kognitif yang lebih berkembang dibandingkan anak dibawah usia 12 tahun. Maka dari itu, berdasarkan paparan diatas, peneliti ingin merancang satu set kartu kuartet yang terdiri dari 32 kartu yang terbagi menjadi 8 kategori dengan teknik ilustrasi botani untuk membantu mengenalkan tanaman obat kepada remaja usia 12 hingga 15 tahun.

\section{METODE PELAKSANAAN}

Pengumpulan dan Analisis Data 
Pada perancangan ini digunakan pendekatan kualitatif baik pada metode perancangan maupun metode pengumpulan data. Data yang digunakan dalam perancangan ini adalah data primer dan sekunder. Data primer terdiri dari observasi dan dokumentasi tanaman obat secara langsung sedangkan data sekunder didapatkan dari studi pustaka tekstual dan visual untuk mendapatkan informasi mengenai tanaman obat tersebut. Analisis data menggunakan metode kualitatif dengan teknik analisis deskriptif. Timeline pengumpulan data, perancangan ilustrasi, hingga perancangan luaran membutuhkan waktu 12 minggu sejak bulan Maret hingga bulan Juni 2021.

Tabel 1. Data yang dikumpulkan

\begin{tabular}{|l|l|l|}
\hline & Macam Data yang Dikumpulkan & \multicolumn{1}{c|}{ Hasil Pengumpulan Data } \\
\hline $\begin{array}{l}\text { Data } \\
\text { Primer }\end{array}$ & $\begin{array}{l}\text { Observasi dan dokumentasi } \\
\text { tanaman obat }\end{array}$ & $\begin{array}{l}\text { Memahami morfologi dan warna } \\
\text { tanaman obat }\end{array}$ \\
\cline { 2 - 3 } & Observasi kartu kuartet & $\begin{array}{l}\text { Memahami struktur kartu kuartet, } \\
\text { variasi tata letak dan gaya gambar }\end{array}$ \\
\hline $\begin{array}{l}\text { Data } \\
\text { Sekunder }\end{array}$ & $\begin{array}{l}\text { Studi pustaka jurnal ilmiah, buku } \\
\text { dan situs daring }\end{array}$ & $\begin{array}{l}\text { Nama tumbuhan, taksonomi, bagian } \\
\text { yang dapat digunakan dan bahan } \\
\text { aktif yang terkandung dalam } \\
\text { tumbuhan }\end{array}$ \\
\hline
\end{tabular}

\section{Uji Coba Media Kartu Kuartet}

Metode uji coba dilakukan pada sampel, yaitu remaja usia 12 hingga 15 tahun berjenis kelamin laki-laki dan perempuan sebanyak 8 orang menggunakan convenience atau opportunity sampling. Proses uji coba dibagi menjadi tiga tahap, yaitu pre-test, uji coba media, dan post-test. Pre-test dan post-test dilakukan secara daring menggunakan Google Forms dengan 10 butir pertanyaan untuk menilai pengetahuan target audiens dalam mengidentifikasi tanaman obat sebelum dan setelah bermain kartu kuartet. Uji coba media kartu kuartet dilakukan secara hybrid (luring dan daring) dengan menerapkan protokol kesehatan sehubungan dengan adanya pandemi COVID-19 untuk mengetahui efektivitas hasil perancangan pada tingkat dasar.

\section{Alur Perancangan}

Adapun strategi perancangan yang diterapkan adalah cyclic strategy, dan terbagi menjadi 1) Pra-produksi; 2) Produksi; dan 3) Pasca-produksi. Pada strategi ini terdapat tahapan feedback dari akademisi dan praktisi yang dapat digunakan sebagai acuan guna 
merevisi rancangan untuk mencapai hasil akhir yang optimal. Akademisi yaitu pihak yang berpengalaman dalam bidang akademik dan desain. Feedback yang diberikan oleh akademisi difokuskan pada perancangan media utama dan pendukung pada tahap praproduksi hingga pasca-produksi. Sedangkan praktisi adalah pihak yang berpengalaman dalam bidang tanaman obat dalam artian mampu mengidentifikasi dan mengenali perbedaan morfologi tanaman obat serta memahami cara pengolahannya. Feedback oleh praktisi difokuskan pada kesesuaian visualisasi tanaman obat pada proses sketsa dan painting pada tahap produksi atau visualisasi.

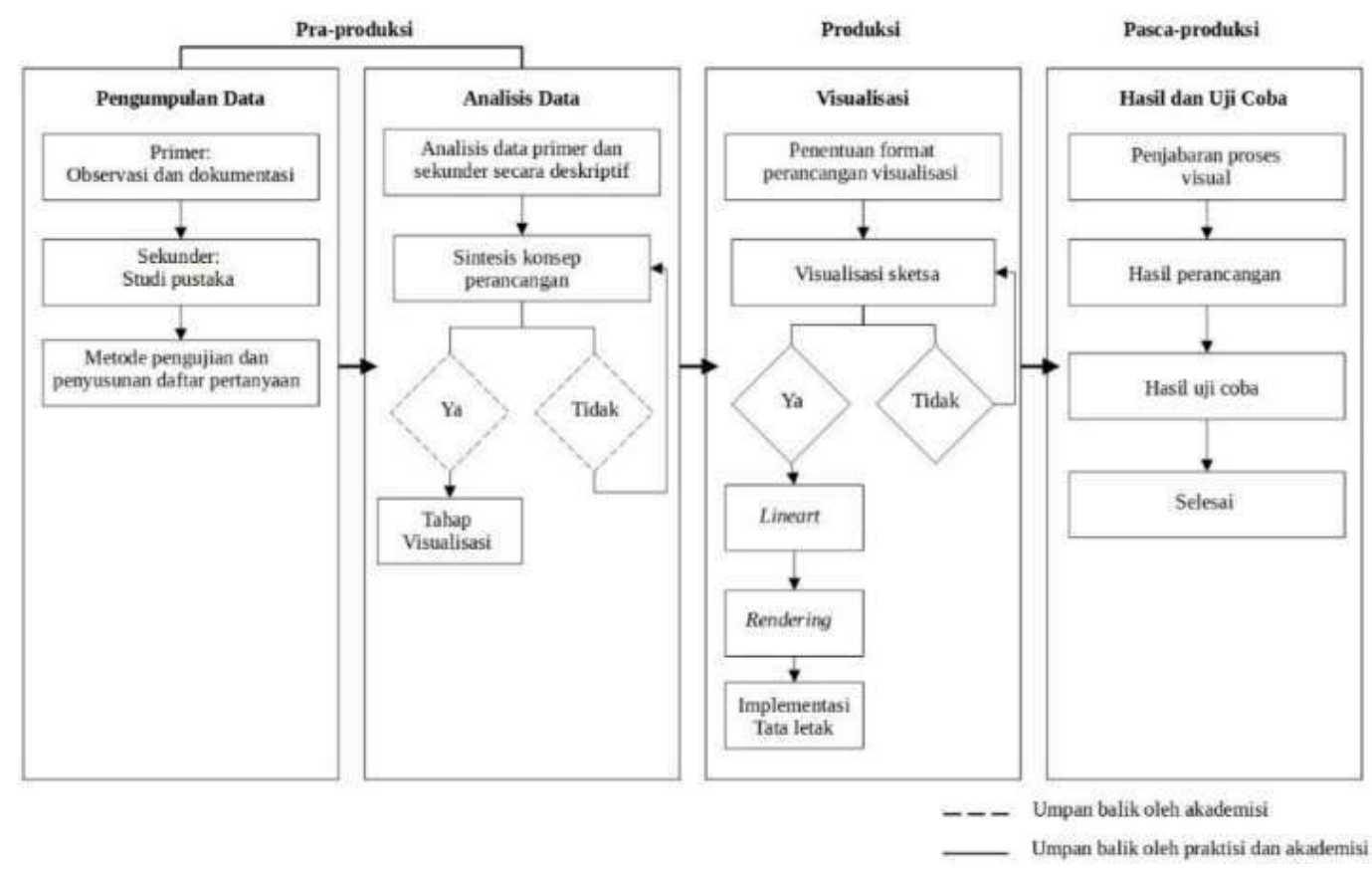

Gambar 1. Bagan alur perancangan

\section{Konsep Perancangan}

Dalam satu set kartu kuartet terdapat 32 kartu yang akan dibagi menjadi 8 kategori berdasarkan bagian-bagian dari tanaman obat, yaitu buah, biji, kulit pohon, aromatik, rimpang, daun, bunga, dan pohon. Pada perancangan ini digunakan skema warna analogus yang terdiri dari warna krem sebagai latar belakang media utama dan media pendukung untuk mempertegas ilustrasi botani, serta warna hijau dan kuning pada elemen dekoratif untuk memberikan kesan natural. Style yang diterapkan pada visualisasi tanaman obat menggunakan seni botani gaya naturalis sedangkan style yang diterapkan pada elemen dekoratif menggunakan gaya Victorian. 
Perancangan visual media utama dan media pendukung diproduksi dengan teknik ilustrasi digital menggunakan metode eyeballing untuk sketsa tanaman obat dengan program Clip Studio Paint untuk tahap pewarnaan dan Paint Tool SAI pada tahap lineart.

\section{Tahapan Perancangan Kartu Kuartet}

Penyusunan

Moodboard

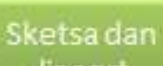
lineart:
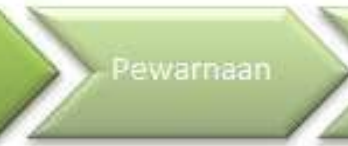

Penataan layout:

Gambar 2. Tahapan perancangan kartu kuartet

1) Penyusunan Moodboard

Moodboard meliputi karya-karya yang mengandung elemen grafis Victorian, kartu permainan, dan penerapan skema warna.

2) Sketsa dan lineart

Sketsa dibuat pada media kertas menggunakan pensil grafit dan pensil warna. Hasil sketsa kemudian dipindai menggunakan scanner dan dilakukan pembuatan lineart secara digital.

3) Pewarnaan

Pewarnaan pada gambar diaplikasikan setelah visualisasi sketsa dan lineart berupa warna dasar yang kemudian dilanjutkan dengan pewarnaan akhir.

4) Pemilihan typography

Jenis typography yang digunakan dalam perancangan media utama adalah Fontaine At Script II yang diaplikasikan pada nama kategori kartu dengan ukuran 26pt, dan Bodoni Bk yang diaplikasikan pada body text nama tumbuhan dan nama spesies tumbuhan pada bagian bawah kartu.

5) Penataan layout

Penataan dari layout dilakukan melalui 4 tahapan, yaitu 1) thumbnail atau idea layout untuk eksplorasi tata letak sebagai kerangka perancangan bingkai, 2) rough layout untuk pengembangan eksplorasi tata letak dengan mempertimbangkan feedback akademisi, 3) comprehensive layout untuk eksplorasi tata letak dengan aset visual yang telah diproduksi serta aplikasi grid golden ratio dan final layout. 

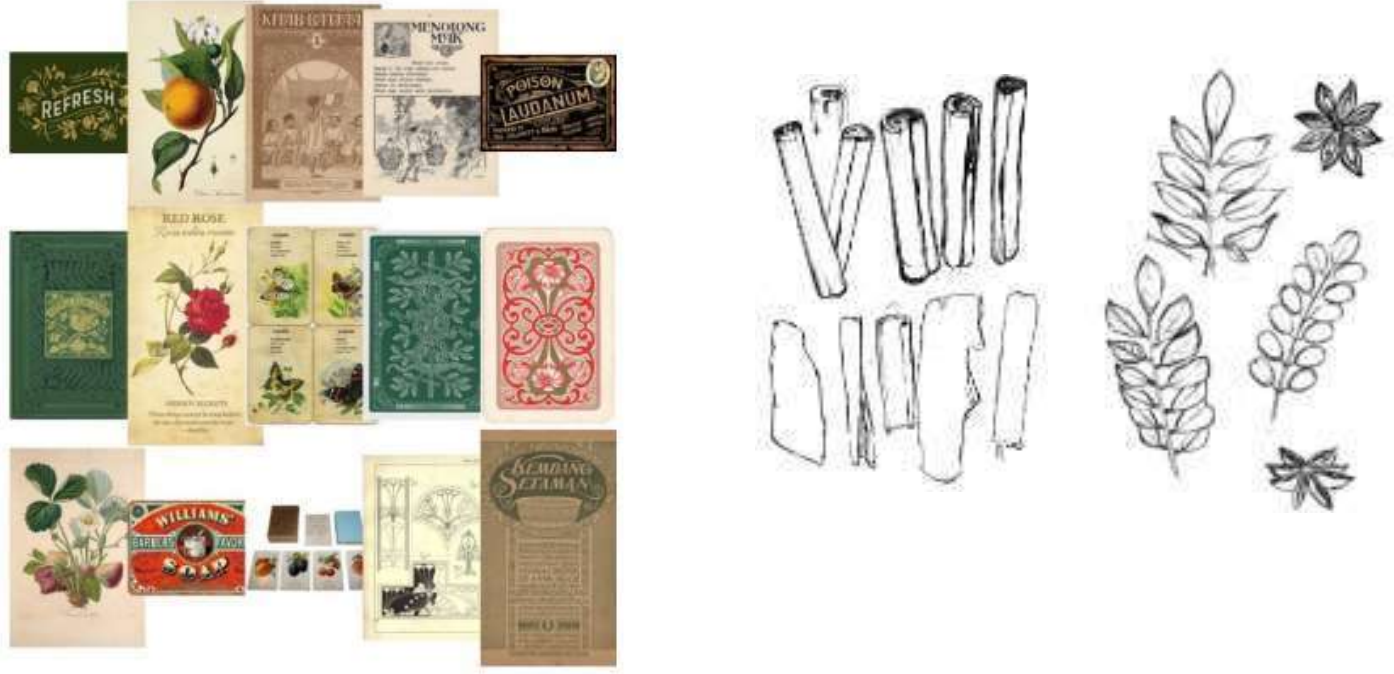

a
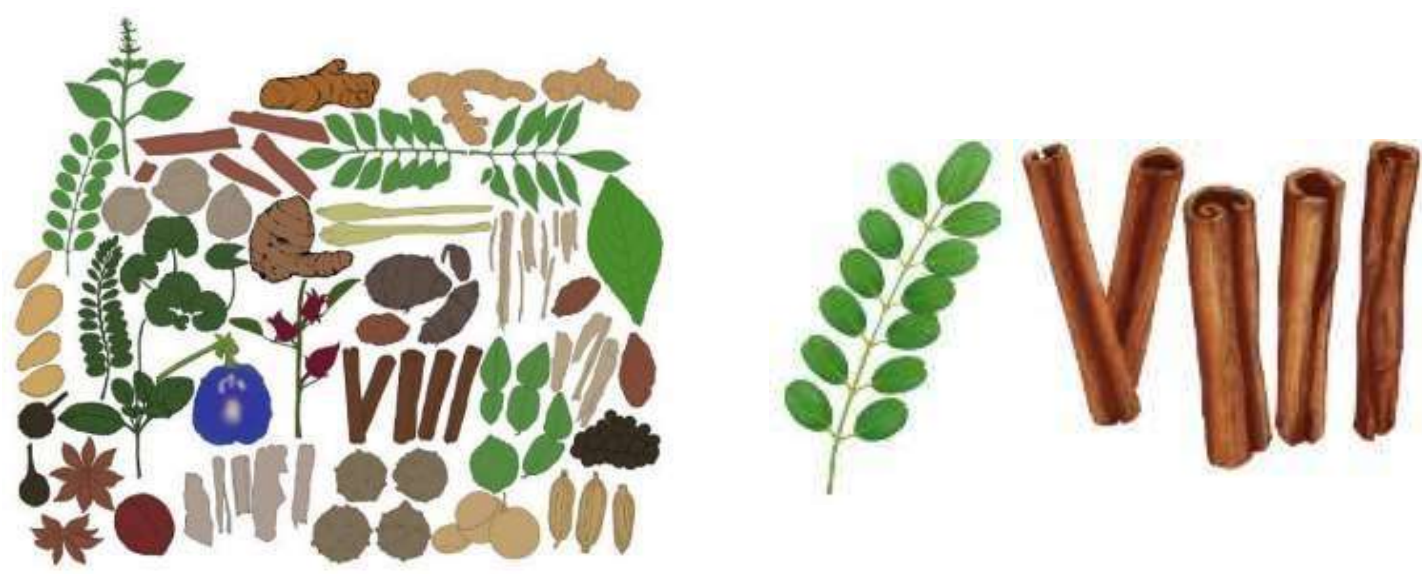

c

d

Gambar 3. Tahapan perancangan kartu kuartet, a) Moodboard; b) Sketsa dan lineart;

c) Pewarnaan dasar; d) Pewarnaan akhir

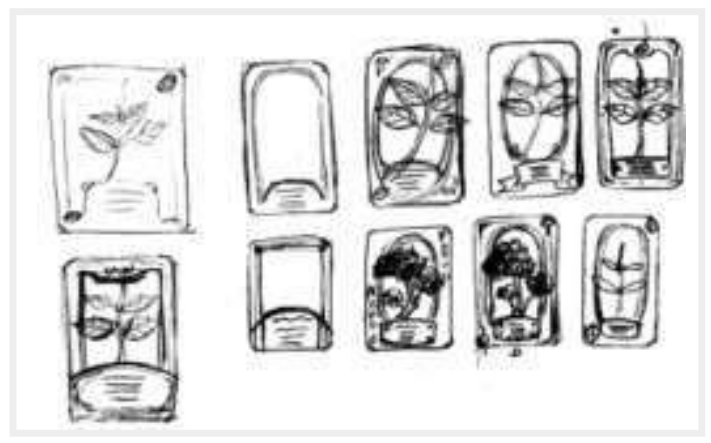

a

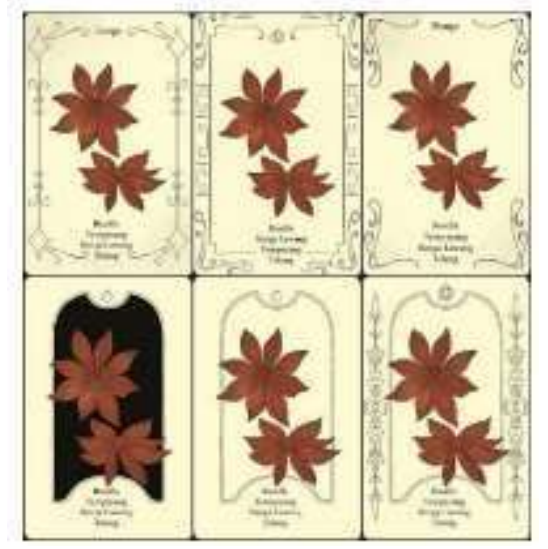

b 


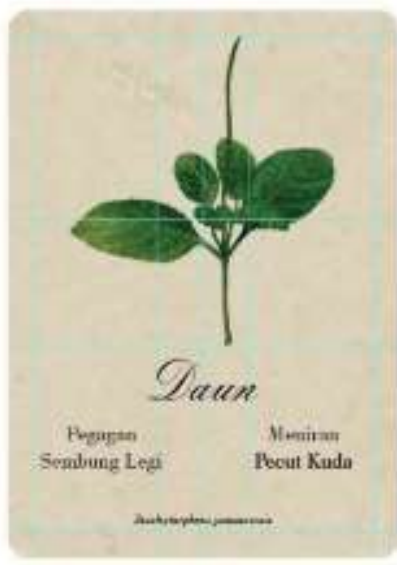

$\mathrm{c}$

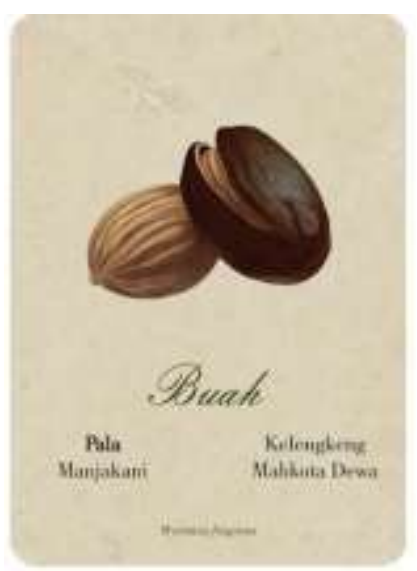

d

Gambar 4. Empat tahapan penataan layout; a) thumbnail/idea layout, b) rough layout, c) comprehensive layout, d) final layout

\section{HASIL DAN PEMBAHASAN}

Perancangan ini menghasilkan kartu kuartet bertema tanaman obat sebagai media utama, dan konten media sosial berupa Instagram carousel dan Instagram Stories, website, teaser, serta desain kemasan sebagai media pendukung. Berikut merupakan beberapa hasil dari visualisasi perancangan kartu kuartet.

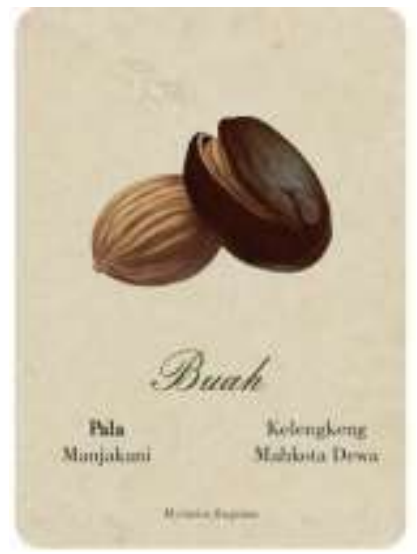

a

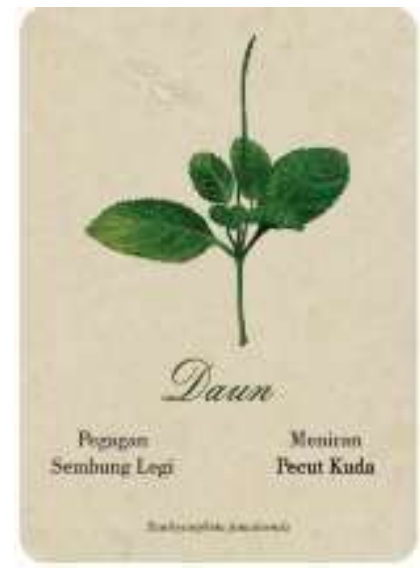

b

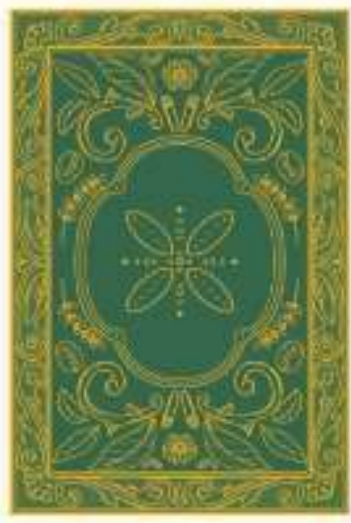

$\mathrm{C}$

Gambar 5. Hasil perancangan media utama kartu kuartet, a) buah pala; b) daun pecut kuda;

$$
\text { c) bagian belakang kartu kuartet }
$$

Perancangan ini juga menghasilkan media pendukung yang terdiri dari desain kemasan, konten media sosial Instagram yang terbagi menjadi Stories dan carousel, teaser video, dan website. 


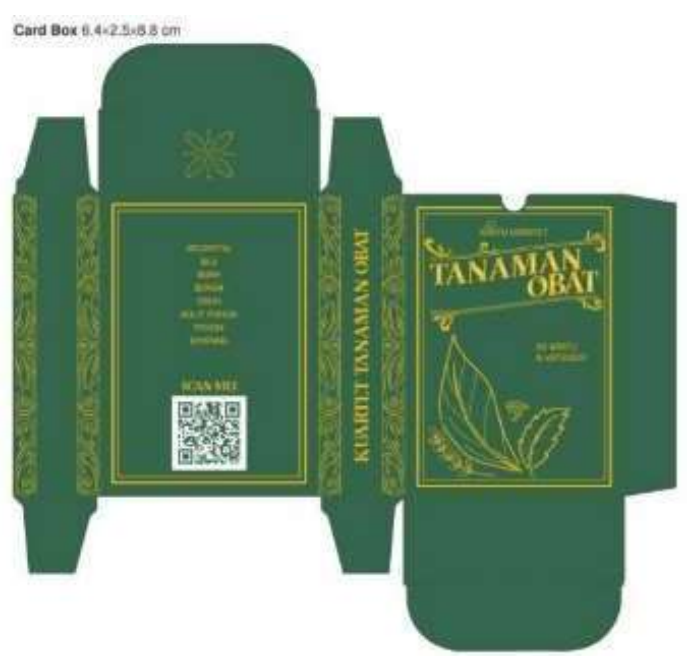

a

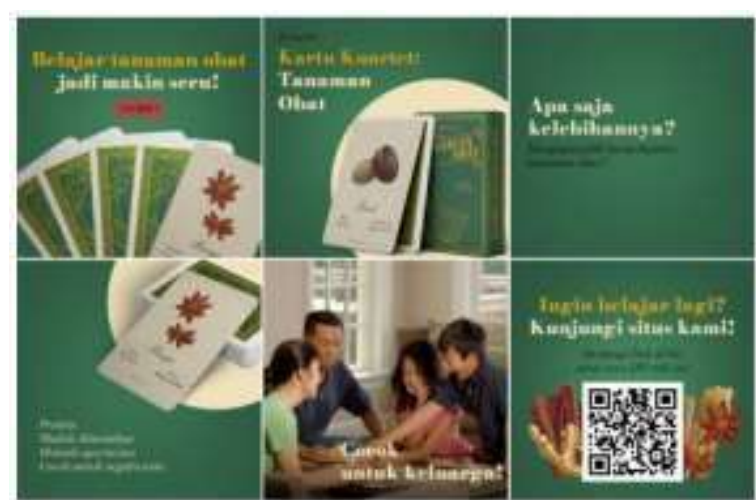

b

Gambar 6. Hasil perancangan media pendukung kartu kuartet, a) Desain kemasan dan,

b) Instagram carousel

Adapun data tekstual yang diperoleh melalui studi pustaka dari jurnal ilmiah, buku, dan artikel daring telah diolah sehingga didapatkan beberapa hasil sebagai berikut:

Tabel 2. Data tekstual tanaman obat

\begin{tabular}{|c|c|c|l|}
\hline No & Kategori & Nama & \multicolumn{1}{c|}{ Keterangan } \\
\hline 1 & Daun & Pegagan & $\begin{array}{l}\text { Genus: Centella } \\
\text { Spesies: Centella asiatica (L.) Urban } \\
\text { Bagian yang digunakan: seluruh bagian } \\
\text { Bahan aktif: Asiaticoside, thankunside, madecassoside, } \\
\text { brahmocide, brahmic acid, madasiatic acid, meso-inositol, } \\
\text { centellose, carotenoids, garam K, Na, Ca, Fe, vellarine, } \\
\text { tannin, mucilago, resin, pektin, gula, vitamin B } \\
\text { Memiliki efek anti-inflamasi dan antipiretik }\end{array}$ \\
\hline 2 & Pohon & Kelor & $\begin{array}{l}\text { Genus: Moringa } \\
\text { Spesies: Moringa oleifera } \\
\text { Bagian yang digunakan: akar, daun dan biji } \\
\text { Bahan aktif: minyak behen; pada kulit akar terdapat minyak } \\
\text { terbang dan pada sel-sel tertentu mengandung myrosine, } \\
\text { emulsine, alkaloida pahit tidak beracun dan vitamin A, B1, } \\
\text { B2 dan C } \\
\text { Memiliki efek anti-inflamasi, antipiretik, dan antiskorbut }\end{array}$ \\
\hline 3 & Aromatik & $\begin{array}{l}\text { Jeruk } \\
\text { Purut }\end{array}$ & $\begin{array}{l}\text { Genus: Citrus } \\
\text { Spesies: Citrus hystrix (DC.) } \\
\text { Bagian yang digunakan: buah } \\
\text { Bahan aktif: pada buahnya terdapat minyak atsiri 1-15\%, } \\
\text { steroid triterpenoid dan tanin 1,8\% sedangkan kulit buah }\end{array}$ \\
\hline
\end{tabular}




\begin{tabular}{|l|l|l|}
\hline \hline & & $\begin{array}{l}\text { mengandung saponin, tannin 1\% steroid triterpenoid, dan } \\
\text { minyak atsiri dengan kandungan sitrat 2-2,5\% } \\
\text { Memiliki efek antispasmodik dan antiseptik }\end{array}$ \\
\hline
\end{tabular}

Berdasarkan hasil uji coba yang dilakukan terhadap 8 remaja usia 12-15 tahun, pada tahap pre-test mengindikasikan bahwa pengetahuan responden mengenai tanaman obat masih tergolong rendah dengan nilai rata-rata 52,5. Skor tersebut membuktikan bahwa responden memiliki potensi yang cukup untuk meningkatkan wawasannya tentang tanaman obat. Setelah dilakukan uji coba media utama, diperoleh data nilai rata-rata 93,75 dari 100 pada tahap post-test yang menandakan adanya peningkatan pada pengetahuan responden mengenai tanaman obat.

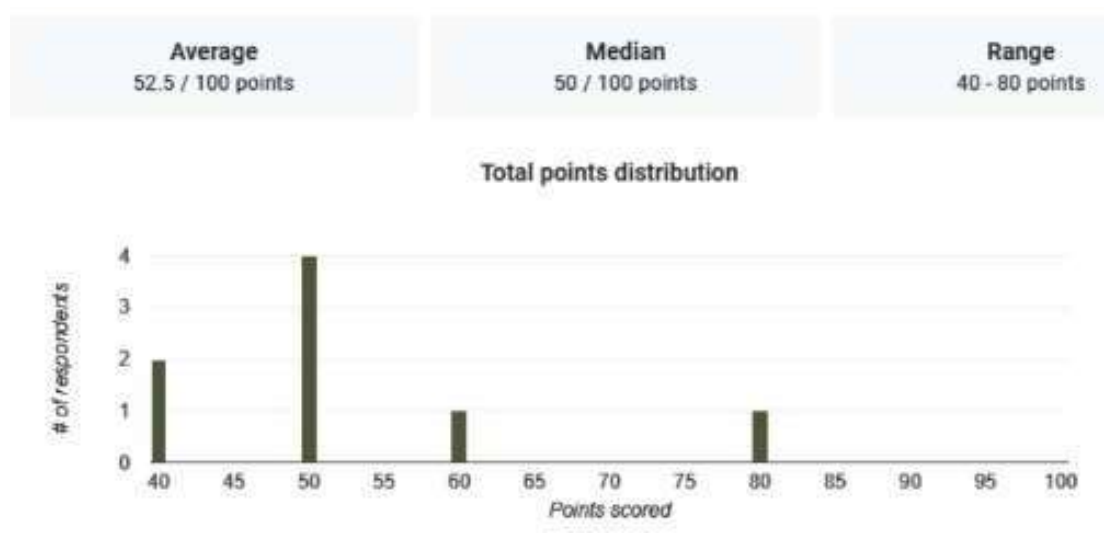

Gambar 7. Rata-rata, median dan range pre-tes

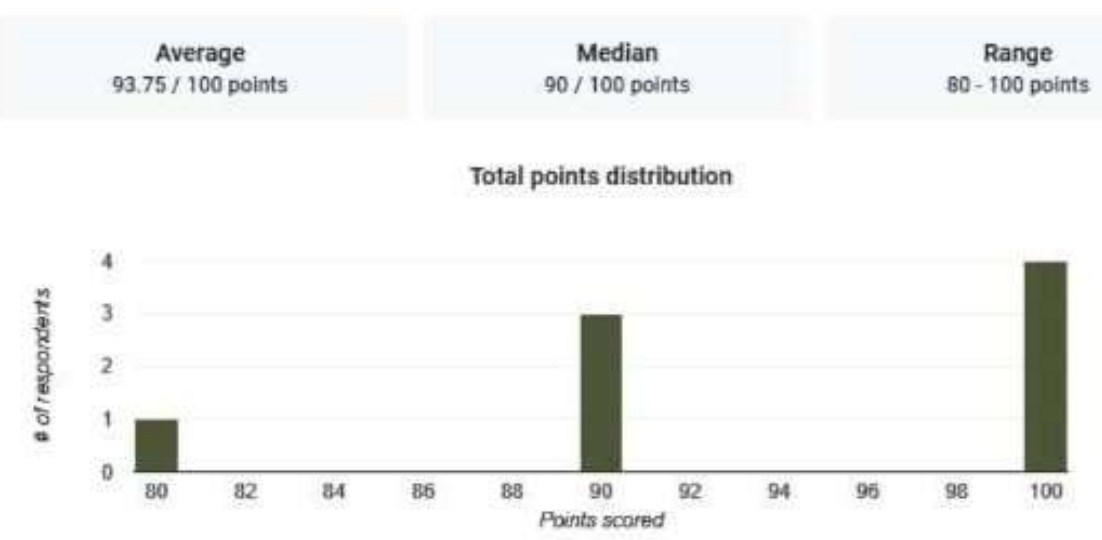

Gambar 8. Rata-rata, median dan range post-test

\section{KESIMPULAN}

Kartu kuartet memiliki potensi yang besar sebagai media pembelajaran alternatif. Namun, pengembangan media pembelajaran tentang tanaman obat khususnya bagi usia anak hingga remaja kurang dimaksimalkan, sedangkan pengenalan tanaman obat sejak dini dapat membantu meningkatkan derajat kesehatan masyarakat sebagai upaya preventif dan kuratif. 
Di lain sisi, potensi ilustrasi botani di Indonesia masih dapat dikembangkan dan dimanfaatkan dalam media pembelajaran tanaman obat, baik dalam kartu kuartet, pembuatan buku maupun yang lainnya. Penggunaan ilustrasi botani dibandingkan foto digital sebagai referensi untuk media edukatif apapun mengenai tanaman obat memiliki akurasi dan nilai seni yang lebih tinggi. Hasil foto digital sebagai referensi tanaman obat berpotensi memberikan informasi yang kurang tepat karena adanya kemungkinan distorsi saat pengambilan gambar dan perbedaan pencahayaan yang dapat merubah bentuk, struktur atau warna asli dari tumbuhan tersebut. Berdasarkan hasil uji coba pre-test dan post-test didapatkan peningkatan pada pengetahuan responden mengenai tanaman obat. Peneliti menyarankan adanya perancangan media edukatif lain mengenai pengenalan tanaman obat.

\section{UCAPAN TERIMA KASIH}

Penulis mengucapkan banyak terima kasih kepada Bapak Aditya Nirwana, S.Sn., M.Sn. dan Bapak Ayyub Anshari Sukmaraga, S.Sn., M.Ds. atas bimbingannya sehingga perancangan ini dapat diselesaikan dengan baik.

\section{DAFTAR PUSTAKA}

Angami, T., Bhagawati, R., Touthang, L., Makdoh, B., Nirmal, Lungmuana, Bharati, K. A., Silambarasan, R., \& Ayyanar, M. (2018). Traditional uses, phytochemistry and biological activities of Parkia timoriana (DC.) Merr., an underutilized multipurpose tree bean: a review. Genetic Resources and Crop Evolution, 65(2), 679-692. https://doi.org/10.1007/s10722-017-0595-0

Azizah, F. N. (2015). Reduksi Rasa Pahit, Sepat, dan Asam Manisan Pala Melalui Perendaman Daging Buah dengan Air Laut. IPB University Scientific Repository.

Badet, C. (2011). Nuts and Seeds in Health and Disease Prevention (1st ed.). Academic Press.

Biodiversity Heritage Library. (1739). v.1 (1737) - A curious herbal - Biodiversity Heritage Library. https://www.biodiversitylibrary.org/item/10361

BPTP Banten. (2016). Mengenal Tanaman Adas. https://banten.litbang.pertanian.go.id/new/index.php/publikasi/folder/958mengenal-tanaman-adas

Budiono, L. (2007). Kajian Aktivitas Antimikroba Ekstrak Kulit Kayu Mesoyi (Cryptocaria massoia) Terhadap Bakteri Patogen dan Pembusuk Pangan.

CAB International. (n.d.). Brassica nigra (black mustard). Retrieved July 10, 2021, from https://www.cabi.org/isc/datasheet/10097

Candrasari, D., Thamrin, G. A. R., \& Arryati, H. (2018). Uji Fitokimia Pada Bagian Kulit Batang Pohon Pulai (Alstonia scholaris). Jurnal Sylva Scienteae, 1(2), 233-242.

Darmaprawira, S. (2002). Warna: Teori dan Kreativitas Penggunanya. Penerbit ITB. 
Dinas Lingkungan Hidup Kabupaten Grobogan. (2014). Mahkota Dewa: Tanaman Obat Sejuta Manfaat. https://dlh.grobogan.go.id/info-lh/berita/12-mahkota-dewatanaman-obat-sejuta-manfaat

Dinas Perumahan Rakyat Kawasan Permukiman dan Pertanahan. (2021). Pohon kelengkeng (Dimocarpus longan). https://dlh.grobogan.go.id/info-lh/berita/12-mahkota-dewatanaman-obat-sejuta-manfaat

Emilda, Muslihatul, H., \& Heriyati. (2017). Analisis Pengetahuan Masyarakat Tentang Pemanfaatan Tanaman Obat Keluarga (Studi Kasus Kelurahan Situgede, Kecamatan Bogor Barat). Sainmatika, 14(1 Juni), 11-21.

Ensiklopedia Dunia. (n.d.). Kemukus. Retrieved July 15, 2021, from http://p2k.itbu.ac.id/id1/1-3070-2950/Kemukus_104264_ensiklopedia-dunia-qitbu.html

Erlindawati, M. (2015). Survei Pengetahuan Masyarakat Tentang Tanaman OBat Keluarga Puskesmas Air Tabit. Photon, 6(1), 115-118.

Gunawan, I. (2013). Metode Penelitian Kualitatif. https://www.academia.edu/download/62137147/3_Metpen-Kualitatif20200218117182-1a60wxc.pdf

Hariana, A. (2013). 262 Tumbuhan Obat dan Khasiatnya. Penebar Swadaya.

Harris, P., \& Ambrose, G. (2011). Basics Design 01: Layout: Second Edition (2nd ed.). AVA Publishing SA.

Haryati, S. (2012). Research \& Development (R\&D) sebagai salah satu Model Penelitian dalam Bidang Pendidikan. Majalah Ilmiah Dinamika, 37(1), 11-26.

Hasanah, U. (2019). Pengembangan Kemampuan Mengenal Bilangan Melalui Penerapan Media Kartu Bergambar di RA Insan Madani Punggur Lampung Tengah. SELING: Jurnal Program Studi PGRA, 5(1 Januari), 92-102.

Hausner, E. A., \& Poppenga, R. H. (2013). Hazards Associated with the Use of Herbal and Other Natural Products. In M. E. Peterson \& P. A. Talcott (Eds.), Small Animal Toxicology (Third Edition) (3rd ed., pp. 335-356). Saunders.

Heller, S., \& Chwast, S. (1988). Graphic Styles: From Victorian To Post-Modern. Harry N. Abrams, Inc.

Hikmat, A., Zuhud, E. A. M., Sandra, E., \& Sari, R. K. (2011). Revitalisasi konservasi tumbuhan obat keluarga (TOGA) guna meningkatkan kesehatan dan ekonomi keluarga mandiri di desa Contoh Lingkar Kampus IPB Darmaga Bogor. Jurnal Ilmu Pertanian Indonesia, 16(2), 71-80.

Himalaya, D. (2017). Pengaruh Pemberian Ekstrak Biji Manjakani (Quercus infectoria Gall) Terhadap Bakteri Vaginosis dan Candida Penyebab Keputihan (Leukorrhea). Journal Of Midwifery, 5(1), 38-44.

Hübert, T., Tiebe, C., \& Banach, U. (2016). Electronic Noises and Tongues in Food Science (1st ed.). Academic Press.

Humphrey, S. J. (2018). Botanical Art with Scientific Illustration. The Crowood Press Ltd. 
ICRAF. (n.d.). Inga timoriana DC. Retrieved July 18, 2021, from http://db.worldagroforestry.org//species/properties/Inga_timoriana

Kamil, R. I., \& Karsono, S. (2013). Penggunaan media permainan kartu kuartet dalam upaya peningkatan pemahaman materi wayang purwa. Jurnal Didaktika Dwija Indria.

Karsono, Sujana, Y., Daryanto, J., \& Yustinus, N. (2014). Penggunaan Kartu Kuartet untuk Meningkatkan Pemahaman Keberagaman Seni Tradisi Nusantara Pada Siswa Sekolah Dasar. Mimbar Sekolah Dasar, 1(1 April), 43-49.

KEHATI. (2017). Pulai Alstonia scholaris. http://kehati.jogjaprov.go.id/detailpost/pulaialstonia-scholaris

Khobir, A. (2009). Upaya Mendidik Anak Melalui Permainan Edukatif. Forum Tarbiyah, 7(2 Desember), 195-208.

Komariyah. (2013). Penggunaan Media Kartu Bilangan untuk meningkatkan Hasil Belajar Penjumlahan dan Pengurangan Bilangan Pecahan pada Mata Pelajaran Matematika Siswa Kelas V SD Al-Amin Surabaya. Jurnal Penelitian Pendidikan Guru Sekolah Dasar, 1(1), 1-5.

Lehti, M. (2012). Writing Guides: Principles of Layout and Design. https://writing.colostate.edu/guides/page. cfm?pageid=735\&guideid=36

Lisnawati, Rohmayani, S., Masdi, \& Sumargono. (2019). Kartu Kuartet Boelang (Budaya Lampung) sebagai Media Edukasi Budaya Lokal di SMPN Bandarlampung. HISTORIA: Jurnal Program Studi Pendidikan Sejarah, 7(2), 243-258.

Machin, D., \& Polzer, L. (2015). Visual Journalism. Macmillan.

Melawati, H., Istiyova, L. R., \& Dewi, R. A. I. (n.d.). Studi Literatur Morfologi, Distribusi Dan Peranan Masoi (Cryptocarya massoy) dalam Kehidupan.

Mulyono, Julia, \& Kurnia, D. (2016). Penggunaan Media Kartu Kwartet untuk Meningkatkan Hasil Belajar Siswa pada Materi Peninggalan Sejarah Hindu-Buddha di Indonesia dalam Mata Pelajaran IPS. Jurnal Pena Ilmiah, 1(1), 481-490.

North Carolina Botanical Garden. (2018). What is Botanical Illustration? https://ncbg.unc.edu/2018/03/08/what-is-botanical-illustration/

Plantamor. (n.d.). Foeniculum vulgare. Retrieved July 8, 2021, from http://plantamor.com/species/info/foeniculum/vulgare

Primadhanty, A., Iryanti, Kardjatin, A., \& Setiyono, B. (2020). Pengaruh Edukasi melalui Kartu Kuartet Terhadap Pengetahuan Anak Kelas 3 Sekolah Dasar Tentang Konsumsi Jajan Sehat.

Pusat Penelitian dan Pengembangan Perkebunan. (2016). Pala (Myristica fragrans) Tanaman Rempah Banyak Manfaat. https://perkebunan.litbang.pertanian.go.id/pala-myristicafragrans-tanaman-rempah-banyak-manfaat/

Puspitasari, I., \& Kurniawan, A. B. (2017). Quartet Card Game: Changing Students' Grammar Mastery in Writing Descriptive Text. ISOLEC (International Seminar on Language, Education, and Culture), 83-87.

Rahmawati, A. (2014). Metode Bermain Peran dan Alat Permainan Edukatif untuk 
Meningkatkan Empati Anak Usia Dini. Jurnal Pendidikan Anak, 3(1 Juni), 382-392.

Rangkadilok, N., Tongchusak, S., Boonhok, R., Chaiyaroj, S. C., Junyaprasert, V. B., Buajeeb, W., Akanimanee, J., Raksasuk, T., Suddhasthira, T., \& Satayavivad, J. (2012). In vitro antifungal activities of longan (Dimocarpus longan Lour.) seed extract. Fitoterapia, 83(3), 545-553.

Redaksi Majalah Adiluhung. (2013). Ulen Sentalu: Museum Batik Magis di Taman Kaswargan. 32.

Rosari, M. I. (2016). Penetapan Kandungan Fenolik Total dan Uji Aktivitas Antioksidan Fraksi Etil Asetat Ekstrak Metanol Daun Kemukus (Piper cubeba L.).

Sadiman, A. (2008). Media Pendidikan Pengertian Pengembangan dan Pemanfaatannya. Raja Grafindo Persada.

Sarwono, J. (2007). Metode Riset untuk Desain Komunikasi Visual. CV. Andi Offset.

Setiyawan, H. (2020). Pemberian Ekstrak Buah Mahkota Dewa (Phaleria macrocarpa (Sheff) Boerl) Terhadap Struktur Mikroanatomi Hepar Tikus Putih (Rattus norvegicus L) Jantan. Seminar Nasional Rekam Medis \& Informasi Kesehatan, 79-84.

Soewardikoen, D. W. (2019). Metodologi Penelitian Desain Komunikasi Visual (Penerbit P).

STTB. (n.d.). Pecut kuda. Retrieved July 18, 2021, from http://kk.sttbandung.ac.id/id1/30422940/Pecut-Kuda_105194_kk-sttbandung.html

Suliyanto. (2017). Metode Penelitian Kualitatif.

Syahputra, A. (2012). Penggunaan Media Permainan Kartu Kuartet pada Pembelajaran Menulis Karangan Narasi. Jurnal Sasindo, 1(2).

The Great Courses Daily. (2017). How To Draw: Perfect Proportion and Measure. https://www.thegreatcoursesdaily.com/how-to-draw-proportion/

Top Trumps. (2013). Top Trumps History. https://archive.is/68qEo

Triatmoko, B., Hertiani, T., \& Yuswanto, A. (2016). Sitotoksisitas Minyak Mesoyi (Cryptocarya massoy) terhadap Sel Vero. E-Jurnal Pustaka Kesehatan, 4(2), 263266.

University of Rochester Medical Center. (2021). Cognitive Development in the Teen Years.

Wang, S., Zhang, C., Yang, G., \& Yang, Y. (2014). Biological properties of 6-Gingerol: A brief review. Natural Product Communications, 9(7), 1027-1030. https://doi.org/10.1177/1934578x1400900736

Ziraluo, Y. P. B. (2020). Tanaman Obat Keluarga dalam Perspektif Masyarakat Transisi (Studi Etnografis pada Masyarakat Desa Bawodobara). Jurnal Inovasi Penelitian, 1(2 Juli), 99-106.

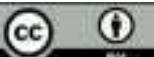

(C) 2021 by authors. Content on this article is licensed under a Creative Commons Attribution 4.0 International license. (http://creativecommons.org/licenses/by/4.0/). 